\title{
Surveillance and the second primary lung cancer: Enhancing our understanding beyond Martini and Melamed
}

\author{
Melanie P. Subramanian, MD, and Varun Puri, MD, MSCI
}

\author{
From the Division of Cardiothoracic Surgery, Washington University School of Medicine, St Louis, Mo. \\ Dr Subramanian received funding support from the T32 NIH Cardiothoracic Training Grant (Grant No. \\ 5T32HL007776023). \\ Disclosures: Authors have nothing to disclose with regard to commercial support. \\ Received for publication Oct 16, 2018; accepted for publication Oct 17, 2018; available ahead of print Nov 27, \\ 2018. \\ Address for reprints: Varun Puri, MD, MSCI, 660 S Euclid Ave, Campus Box 8234, St Louis, MO 63110 (E-mail: \\ varunpuri@wustl.edu). \\ J Thorac Cardiovasc Surg 2019;157:1203-4 \\ $0022-5223 / \$ 0.00$ \\ Published by Elsevier Inc. on behalf of The American Association for Thoracic Surgery \\ https://doi.org/10.1016/j.jtcvs.2018.10.062
}

Computed tomographic (CT) imaging surveillance after lung cancer resection is an important part of survivorship care and allows for the early detection of recurrence or second primary lung cancer. Traditionally, determination of second primary lung cancer has been based on features including histologic type, location, time interval between presentation and initial cancer diagnosis according to criteria published by Martini and Melamed ${ }^{1}$ in 1975. Understanding of the differences in outcomes between synchronous primary lung cancer and metachronous primary lung cancer, however, remains suboptimal.

In their study in this issue of the Journal focusing on patients undergoing CT surveillance after lung cancer resection, Wang and colleagues ${ }^{2}$ compared imaging characteristics, histology, and long-term outcomes of patients with either synchronous primary lung cancer or metachronous primary lung cancer. They observed that synchronous and metachronous primary lung cancers differed in characteristics of imaging density, growth rate, and interval between identification and diagnosis. Despite these differences, more than $80 \%$ of synchronous and metachronous primary lung cancers alike were diagnosed at clinical stage I. This translated to a relatively high percentage of patients $(>75 \%)$ receiving curative intent therapy by either surgery or stereotactic body radiation therapy. Despite the second primary lung cancer, long-term survival remained high. Five-year second lung cancer survival was $73 \%$, with no significant differences observed between patients with synchronous and metachronous primary lung cancers.

What do the findings derived from this study by Wang and colleagues $^{2}$ tell us? First, CT surveillance in patients undergoing resection of non-small cell lung cancer is critical and can potentially make an impact on long-term survival. As noted by Wang and colleagues, ${ }^{2}$ all patients but one had the second primary lung cancer identified at the

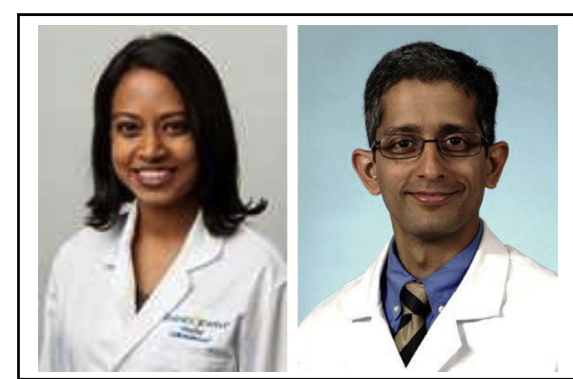

Melanie P. Subramanian, MD (left), and Varun Puri, MD, MSCl (right).

\section{Central Message}

CT surveillance plays an important role in identifying key features of second primary lung cancer. When second primary lung cancer is detected early, patients can have good long-term survival.

See Article page 1196.

asymptomatic stage. Presence of symptoms at the time of diagnosis of recurrence or second primary lung cancer has previously been demonstrated to be associated with detection at later stage and worse overall survival. ${ }^{3,4}$ Whether findings from this study can be generalized to the lung cancer population at large, however, is difficult to say. Wang and colleagues $^{2}$ examined patterns of second primary lung cancer in patients undergoing CT scans at fixed 6-month intervals during the first 2 years. In actual practice, surveillance is much more heterogeneous in both imaging modality and frequency, and adherence to established imaging surveillance guidelines has been documented to be as low as $60 \%$.

Currently, histologic subtyping and molecular profiling serve as important adjuncts to traditional Martini and Melamed criteria (known as modified Martini and Melamed criteria) and enhance our understanding of tumor heterogeneity in second primary lung cancers. ${ }^{6}$ In a study of genomic profiles of 15 synchronous primary lung tumors removed from 6 patients, Liu and associates ${ }^{7}$ found that tumors from the same patient were no more similar to each other than were tumors of different patients. Testing of tumors for mutations genes such as EGFR, KRAS, or TP53 has become routine when there is concern of synchronous or metachronous primary lung cancer. ${ }^{8}$ Further advances in surveillance, histologic subtyping, and mutational 
analysis can inform the decision-making process and optimize long term outcomes of patents with second primary lung cancer.

\section{References}

1. Martini N, Melamed MR. Multiple primary lung cancers. J Thorac Cardiovasc Surg. 1975;70:606-12.

2. Wang Y, Yeung JC, Hanna WC, Allison F, Paul NS, Waddell TK, et al. Metachronous or synchronous primary lung cancer in the era of computed tomography surveillance. J Thorac Cardiovasc Surg. 2019;157:1196-202.

3. Calman L, Beaver K, Hind D, Lorigan P, Roberts C, Lloyd-Jones M. Survival benefits from follow-up of patients with lung cancer: a systematic review and metaanalysis. J Thorac Oncol. 2011;6:1993-2004.
4. Lou F, Sima CS, Rusch VW, Jones DR, Huang J. Differences in patterns of recurrence in early-stage versus locally advanced non-small cell lung cancer. Ann Thorac Surg. 2014;98:1755-60; discussion 1760-1.

5. Erb CT, Su KW, Soulos PR, Tanoue LT, Gross CP. Surveillance practice patterns after curative intent therapy for stage I non-small-cell lung cancer in the Medicare population. Lung Cancer. 2016;99:200-7.

6. Antakli T, Schaefer RF, Rutherford JE, Read RC. Second primary lung cancer. Ann Thorac Surg. 1995;59:863-6; discussion 867.

7. Liu Y, Zhang J, Li L, Yin G, Zhang J, Zheng S, et al. Genomic heterogeneity of multiple synchronous lung cancer. Nat Commun. 2016;7:13200.

8. Goto T, Hirotsu Y, Mochizuki H, Nakagomi T, Shikata D, Yokoyama Y, et al. Mutational analysis of multiple lung cancers: discrimination between primary and metastatic lung cancers by genomic profile. Oncotarget. 2017; 8:31133-43. 